\title{
Massive true thymic hyperplasia in a 3-month-old infant: case report and literature review
}

\author{
Min Yang ${ }^{1 *}$, Lin Zeng $^{2^{*} \oplus}$, Yi ji ${ }^{1 \oplus}$, Bo Xiang ${ }^{1 \oplus}$, Zhi-cheng $\mathrm{Xu}^{1 \oplus}$ \\ ${ }^{1}$ Department of Pediatric Surgery, West China Hospital of Sichuan University, Chengdu, Sichuan Province, the People's Republic of \\ China; ${ }^{2}$ President \& Dean's Office, West China Hospital of Sichuan University, Chengdu, Sichuan Province, the People's Republic of \\ China.
}

\begin{abstract}
Background. True thymic hyperplasia (TTH) is characterized as a distinct increase in both size and weight of thymus, which retains normal microscopic and immunohistochemical appearances. Massive true thymic hyperplasia (MTTH) is an extremely rare but significant subtype of TTH in pediatric ages due to its potentially serious consequences. It was reported that the age of cases with MTTH was predominantly between 1 and 15 years, while those before 1 year rarely occurred. By presenting the diagnosis and treatment process of our case as well as reviewing the related literature, we aimed to analyze the clinical characteristics of MTTH for patients younger than 1 year.
\end{abstract}

Case. A 3-month-old male infant was admitted to our department with a chief complaint of gradually increasing polypnea over 9 days, whose preoperative imaging examination showed a large intrathoracic soft tissue shadow predominantly on the right side. The percutaneous fine-needle biopsy guided by ultrasonography was performed to identify its diagnosis. However, proliferating lymphocytes and Hassall's corpuscles were seen microscopically in the biopsy tissues, which were immunohistochemically positive for CD3, CD19, CD20, CD99, TdT, PCK and Ki67 (>90\%). Due to the aggravating symptoms, a second operation with total thymectomy was carried out successfully for this infant, which confirmed the diagnosis of TTH again by both morphological study and immunohistochemical staining from the surgical specimen.

Conclusions. By reviewing the literature, there were only 10 cases with MTTH reported between 1975 and 2020 for children aged $<1$ year of life, together with our present one. In MTTH patient's sex had an obviously male predominance $(70 \%)$. Nine out of 10 presented initial symptoms or signs related to respiratory system and 6 patients showed respiratory distress. All patients were successfully treated by surgical thymectomy without any postoperative complications. The prognosis of MTTH was very successful.

Key words: true thymic hyperplasia, massive true thymic hyperplasia, infant, biopsy, thymectomy.

The thymus is an important immune organ for children, whose size and weight decreases with age. ${ }^{1,2}$ True thymic hyperplasia (TTH) is characterized as a distinct increase in both size and weight of thymus, which retains normal microscopic and immunohistochemical appearances. ${ }^{3-5}$ Massive true thymic hyperplasia (MTTH) is an extremely rare but significant

\section{Zhi-cheng Xu}

xzcxewk@163.com

Received 30th August 2020, revised 8th November 2020, accepted 4th December 2020.

*These authors contribute equally as co-first authors. subtype of TTH in pediatric ages due to its potentially serious consequences, which is rather difficult to be distinguished from anterior mediastinal tumors such as thymic lymphoma and thymoma. ${ }^{6}$ MTTH rarely occurs in patients younger than 1 year. ${ }^{1,2}$ Here, we report a 3-month-old infant who was clinically diagnosed as MTTH. We also reviewed the clinical features of MTTH for children aged $<1$ year of life in the literature.

\section{Case Report}

A 3-month-old male infant was admitted to our department on July 20th 2019, with a chief 
complaint of gradually increscent polypnea over 9 days, especially after crying or aggravating activities. Without any specific past medical history or family history, the boy weighed $7 \mathrm{Kg}$ on admission, with a height of $65 \mathrm{~cm}$. Physical examinations revealed absent breath sounds in the right hemithorax. Laboratory investigations demonstrated a slight leukocyte rise of $13.29 \times 10^{9} / \mathrm{L}$ with $81.3 \%$ lymphocytes, while tumor markers such as alpha fetoprotein and neuronspecific enolase were in the normal range. Chest $\mathrm{X}$-ray showed a large intrathoracic soft tissue shadow predominantly on the right side, occupying most of the right hemithorax (Fig. 1a).

A percutaneous fine-needle biopsy guided by color Doppler ultrasonography (US) was performed for this infant on July 24th 2019, in which 6 pieces of tissues from different directions inside the lesion were obtained to identify diagnosis. This patient was transferred to a pediatric medical ward on July 26th 2019 and prepared to receive targeted antitumor chemotherapy based on biopsy results. Unexpectedly, proliferating lymphocytes and Hassall's corpuscles were seen microscopically in the biopsy tissues, which were immunohistochemically positive for CD3, CD19, CD20, CD99, TdT, PCK and Ki67 (>90\%) (Fig. 2a-2h). The fluorescence in situ hybridization (FISH) of EBER 1/2 was also negative and gene rearrangement (PCR+GENESCAN) detected no TCRG amplification peak, which further supported the pathological diagnosis of TTH.

On August 27th 2019, this infant was referred to our department again for surgical resection by his family. Thoracic contrast-enhanced computed tomography (CT) was carried out, which showed a solid inhomogeneous predominantly hypodense hypervascularized soft tissue mass in the right thoracic cavity. This lesion was contiguous to the anterior
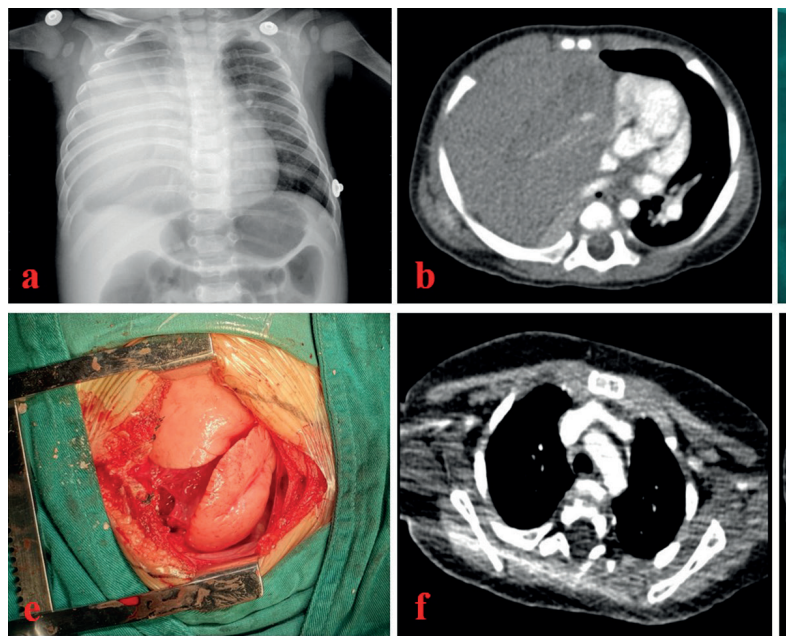
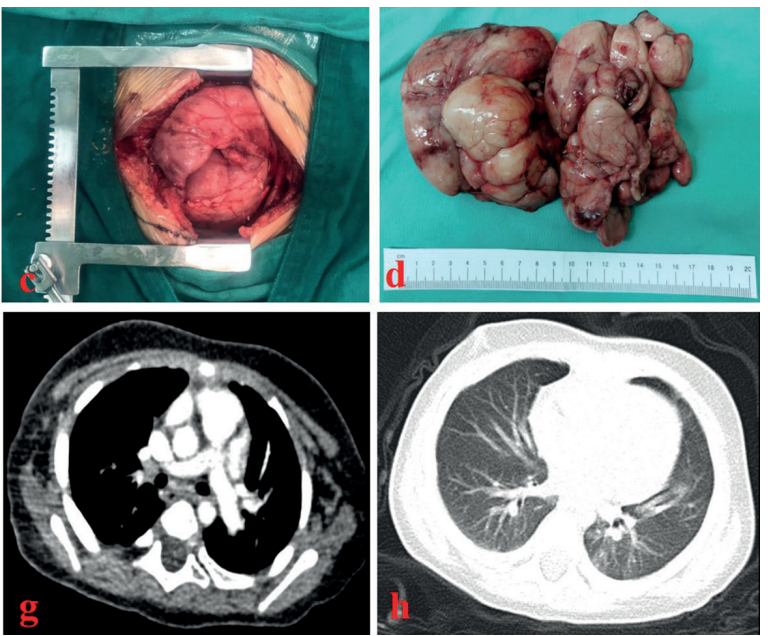

Fig. 1. a. Chest $X$-ray showed a large intrathoracic soft tissue shadow predominantly on the right side, involving most of the right hemithorax. b. Thoracic contrast-enhanced CT detected a solid predominantly hypodense, heterogeneous, hypervascularized soft tissue mass in the right thoracic cavity, significantly compressing the right lung with complete atelectasis and compressing the heart and large blood vessels with mediastinal shift towards the left. c. Exploratory thoracotomy found that a giant mass originating from the mediastinum filling most of the right thoracic cavity, pushing the right lung backwards and upwards. d. The mass was lobulated, fatty and soft in texture with clear boundary and complete capsule, measuring about $17 \times 11 \times 4 \mathrm{~cm}$ and $240 \mathrm{~g}$ in weight. e. After resection of the whole mass, the right lung immediately re-expanded well with normal function. f. Four months after second operation, thoracic contrast-enhanced CT detected no recurrence and residual of lesion in the mediastinum or thoracic cavity. g. Ten months after second operation, thoracic contrast-enhanced CT also detected no recurrence and residual of lesion in the mediastinum or thoracic cavity. h. The patient's right lung expanded well 4 months after his second operation. 
mediastinum, significantly compressing the right lung with complete atelectasis and squeezing the heart and large blood vessels with mediastinal shift towards the left, while the normal thymus was not well identified (Fig. $1 b)$.

On August 30th 2019, under general inhalation anesthesia with endotracheal intubation, we performed a right anterolateral exploratory thoracotomy for this infant, in which a giant mass originating from the mediastinum was detected (Fig. 1c). The mass occupied most of the right thoracic cavity, leading to the right lung being visibly pushed backwards and upwards. Unfolding the mediastinal pleura, the mass was lobulated, fatty and soft in texture with clear boundary and complete capsule, which was compatible with that of thymus. During the operation, the fast-frozen pathologic examination from tissues of the mass indicated thymus hyperplasia once again. Finally, thymectomy with removal of homogeneous pale tissue was performed successfully for the infant, in which the whole mass measured about $17 \times 11 \times 4 \mathrm{~cm}$ in volume and $240 \mathrm{~g}$ in weight (Fig. 1d). After resection, his right lung immediately re-expanded with normal function (Fig. 1e).
The postoperative course of this infant was uneventful. This patient was transferred to a general ward from the intensive care unit on the fifth postoperative day with a normal respiratory pattern and discharged from our hospital on September 8th 2019. The postoperative pathological report from the surgical specimen by both morphological study and immunohistochemical staining confirmed the diagnosis of TTH as well, which was in agreement with the previous results by fineneedle biopsy (Fig. 2). Ten months after the second operation, the boy had no new symptom and recurrence was detected. The chest CT detected no recurrence and residual of lesion in the mediastinum or thoracic cavity (Fig. 1f; Fig. $1 \mathrm{~g})$, and his right lung expanded well (Fig. 1h).

Patient has provided informed consent for publication of the case.

\section{Discussion}

Located in the anterior mediastinum, the thymus embryologically derives from the ventral pouch of the third and fourth branchial arch. The size and weight of thymus varies with age. For a newborn, the mean weight of thymus is approximately $15 \mathrm{~g}$. For infant at 1 to 3 years,
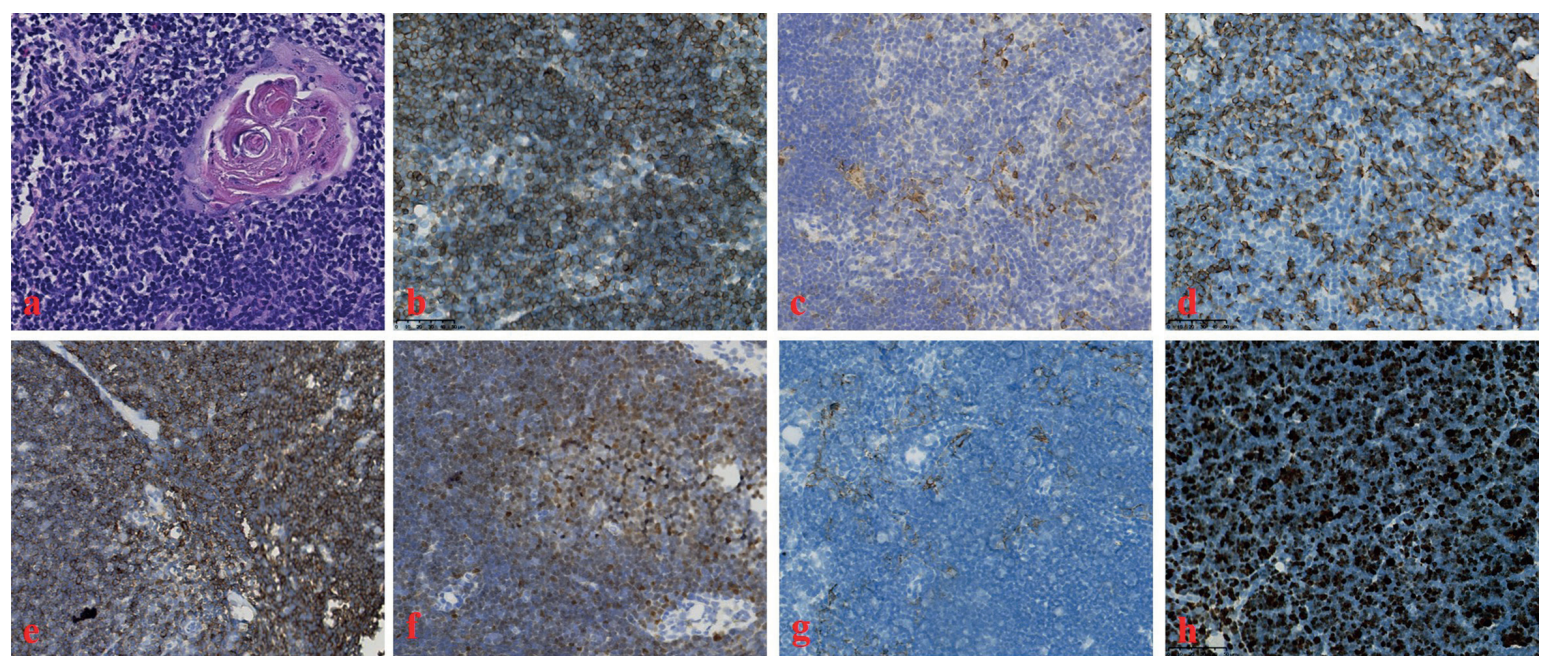

Fig. 2. Pathological analysis and immunohistochemical staining of the lesions by 400-fold optical microscope: a. Hematoxylin and eosin stain; b. Strong expression of CD3; c. Strong expression of CD19; $\mathbf{d}$. Strong expression of CD20; e. Strong expression of CD99; f. Strong expression of TDT; g. Strong expression of PCK; h. Strong expression of $\mathrm{Ki}-67$ (>90\%). 
normal thymus weight ranges between 23 and $55 \mathrm{~g} \pm 13 \mathrm{~g}$. Thymus gradually involutes during the first 3 to 4 years of life. ${ }^{1,2}$ The thymus of a 3-month-old boy in our study weighed $240 \mathrm{~g}$, notably beyond the average.

Thymus is the primary site of T-cell proliferation and maturation, whose hyperplasia has been usually defined by three classifications. ${ }^{3,5,7}$ One is TTH with distinct increase in both size and weight, which retains normal microscopic and immunohistochemical appearances. The second one is lymphoid hyperplasia consisting of lymphoid cells with germinal centers predominates, regardless of the size or weight of thymus. The third one is lymphoepithelial sialadenitis like thymic hyperplasia. The second classification is often associated with myasthenia gravis, while the present case fell into the first category. As in our case (Fig. 2a-2h), TTH is histologically normal thymic tissue, which is composed of lobules with clearly demarcated cortex, medulla, and Hassall corpuscles. ${ }^{5}$ Referring to the radiologic findings, TTH usually demonstrated a massively enlarged lesion extending from anterior mediastinum to the right upper and middle pleural cavity with underlying lung collapse without compression of the airway. ${ }^{8}$ The present case showed similar imaging results, which was also rather difficult to be distinguished with other thymus masses preoperatively (Fig. 1a, 1b).

As a variant of TTH, MTTH is usually asymptomatic but occasionally produces symptoms related to compression of adjacent structures, such as dyspnea, dysphagia, pulmonary infections, or less commonly as an incidental finding. ${ }^{6}$ Although there are no generally accepted definitions of MTTH, the following guidelines have been proposed in the literatures: ${ }^{5-8}$ (i) the thymus should be greater than the heart shadow on posterior-anterior chest radiograph; (ii) it should weigh several times the expected weight for the age of the patient; (iii) it should represent more than $2 \%$ of the body mass. According to the description of clinical features above, our case met all three criteria.
The clinical manifestations and instrumental examinations of MTTH are atypical, which is often misdiagnosed as either anterior mediastinal tumor-like lesions, such as thymic lymphoma, thymoma, and germ cell tumors, or other causes of thymus enlargement, such as myasthenia gravis. ${ }^{2,8}$ Distinguishing these entities requires pathological analysis of issues by fine-needle biopsy or surgical resection. In the present study, mediastinal malignancy was highly suspected for this infant at the beginning, while analysis by percutaneous US-guided fineneedle biopsy was compatible with TTH. This situation might be caused by the misdiagnosis from insufficient or inaccurate biopsy tissues, which was however confirmed once again by the analysis of resected specimens from his second operation. Finally, this boy was managed surgically with complete excision of thymus, as advocated by most authors., ${ }^{5,8-10}$

It has been reported that the age of cases with MTTH is predominantly between 1 and 15 years, while those before 1 year or after 15 years rarely occurs. ${ }^{1,2,8}$ To the best of our knowledge, there were only 10 cases with MTTH reported in the literature between 1975 and 2020 in children aged $<1$ year of life, including our present case (Table I). ${ }^{2,5,6,11-16}$ We identified 7 males and 3 females, whose mean age at diagnosis was 5.9 months, ranging from the youngest one of 1 months to the eldest of 11 months. Nine out of 10 presented initial symptoms or signs related to the respiratory system and 6 patients showed respiratory distress. Only 3 patients received glucocorticoids therapy which all failed to shrink the volume of thymus and to relieve the symptoms. Finally, all patients were successfully treated by surgical thymectomy without any postoperative complications. The mean weight and mean largest diameter of resected thymus was $296.4 \mathrm{~g}$ (ranging from 200 $\mathrm{g}$ to $550 \mathrm{~g}$ ) and $14 \mathrm{~cm}$ (ranging from $8.5 \mathrm{~cm}$ to $18 \mathrm{~cm}$ ), respectively. According to the available prognostic data of each case, 8 patients were thoroughly asymptomatic at follow-up (80\%). One patient with Beckwith-Wiedemann Syndrome had a hepatic hemangioma and was 
Table I. Clinical features of MTTH in children aged $<1$ year of life, including present case.

\begin{tabular}{|c|c|c|c|c|c|c|c|}
\hline Authors & Date & Sex & Age & Symptoms & Treatments & Thymus size & Prognosis (age) \\
\hline Katz et al $^{11}$ & 1977 & M & $7 \mathrm{mo}$ & Hepatomegaly & $\begin{array}{l}\text { Surgical } \\
\text { thymectomy }\end{array}$ & $\begin{array}{c}224 \mathrm{~g} \\
9 \times 8 \times 6 \mathrm{~cm}\end{array}$ & Asymptomatic (4 y) \\
\hline Lamesch et al ${ }^{12}$ & 1982 & $\mathrm{~F}$ & $7 \mathrm{mo}$ & Respiratory distress & $\begin{array}{l}\text { 1. Steroid } \\
\text { (ineffective) } \\
\text { 2. Surgical } \\
\text { thymectomy }\end{array}$ & $\begin{array}{c}230 \mathrm{~g} \\
18 \times 11 \times 8.5 \mathrm{~cm}\end{array}$ & Asymptomatic (7 y) \\
\hline Linegar et al ${ }^{6}$ & 1993 & $\mathrm{~F}$ & $2 \mathrm{mo}$ & Respiratory distress & $\begin{array}{l}\text { Surgical } \\
\text { thymectomy }\end{array}$ & $220 \mathrm{~g}$ & Asymptomatic (3 mo) \\
\hline Lee et $\mathrm{al}^{13}$ & 1996 & $\mathrm{M}$ & & $\begin{array}{l}\text { Fever and upper } \\
\text { respiratory } \\
\text { symptoms }\end{array}$ & $\begin{array}{l}\text { Surgical } \\
\text { thymectomy }\end{array}$ & $500 \mathrm{~g}$ & Asymptomatic ${ }^{\mathrm{A}}$ \\
\hline Woywodt et al ${ }^{14}$ & 1999 & M & $11 \mathrm{mo}$ & Pneumonia & $\begin{array}{l}\text { Surgical } \\
\text { thymectomy }\end{array}$ & $\begin{array}{c}550 \mathrm{~g} \\
17 \times 5 \times 3 \mathrm{~cm}\end{array}$ & Asymptomatic (6 y) \\
\hline Regal et $\mathrm{al}^{2}$ & 2007 & M & $5 \mathrm{mo}$ & Respiratory distress & $\begin{array}{l}\text { Surgical } \\
\text { thymectomy }\end{array}$ & $380 \mathrm{~g}$ & Asymptomatic (2 y) \\
\hline Tan et $\mathrm{al}^{5}$ & 2010 & F & $9 \mathrm{mo}$ & $\begin{array}{l}\text { Fever and upper } \\
\text { respiratory } \\
\text { symptoms }\end{array}$ & $\begin{array}{l}\text { 1. Steroid } \\
\text { (ineffective) } \\
\text { 2. Surgical } \\
\text { thymectomy }\end{array}$ & $\begin{array}{c}200 \mathrm{~g} \\
17.5 \times 11 \times 5 \mathrm{~cm}\end{array}$ & $\begin{array}{l}\text { Asymptomatic (at } \\
\text { the discharge from } \\
\text { hospital) }\end{array}$ \\
\hline Sayed et $\mathrm{al}^{15}$ & 2016 & M & $3 \mathrm{mo}$ & $\begin{array}{l}\text { Respiratory distress, } \\
\text { failure to thrive }\end{array}$ & $\begin{array}{l}\text { Surgical } \\
\text { thymectomy }\end{array}$ & $\begin{array}{c}219.7 \mathrm{~g} \\
14 \times 12 \times 5 \mathrm{~cm}\end{array}$ & $\begin{array}{l}\text { Hepatic hemangioma } \\
\text { and managed } \\
\text { conservatively }^{\mathrm{B}}\end{array}$ \\
\hline Weis et $\mathrm{al}^{16}$ & 2017 & M & $1 \mathrm{mo}$ & Respiratory distress & $\begin{array}{l}\text { 1. Steroid } \\
\text { (ineffective) } \\
\text { 2. Surgical } \\
\text { thymectomy }\end{array}$ & $\begin{array}{c}200 \mathrm{~g} \\
8.5 \times 7.5 \times 3.8 \mathrm{~cm}\end{array}$ & $\begin{array}{l}\text { Recurrence and } \\
\text { 2nd resection, } \\
\text { asymptomatic }(1 \mathrm{y})^{\mathrm{C}}\end{array}$ \\
\hline Present case & 2020 & $\mathrm{M}$ & $3 \mathrm{mo}$ & Respiratory distress & $\begin{array}{l}\text { Surgical } \\
\text { thymectomy }\end{array}$ & $\begin{array}{c}240 \mathrm{~g} \\
17 \times 11 \times 4 \mathrm{~cm}\end{array}$ & Asymptomatic (1 y) \\
\hline
\end{tabular}

A: Author did not list time of follow-up.

B: Patient was clinically diagnosed as MTTH with Beckwith-Wiedemann syndrome. At follow-up, he presented with hepatic hemangioma which was managed conservatively.

c: Patient showed recurrence of MTTH soon after first surgery. A second surgical resection was performed again. Child asymptomatic at $1 \mathrm{y}$ follow-up.

MTTH: massive true thymic hyperplasia, M: male, F: female.

managed conservatively. One patient showed a recurrence of MTTH soon after the first surgery and a second surgical resection was performed successfully, who was asymptomatic at 1 year old.

In conclusion, we described a case of 3-monthold infant who was clinically diagnosed with MTTH. Together with our present one, there were only 10 cases with MTTH reported in the literature between 1975 and 2020 in children aged
$<1$ year of life. Patients gender in MTTH had an obviously male predominance. Glucocorticoids might be ineffective, while surgical thymectomy could be perfectly performed for the patients. The prognosis of MTTH was very well.

\section{Author contribution}

In this paper, M. Yang and L. Zeng. Contributed equally to this work as co-first authors: $\mathrm{ZCXu}$; contributed as senior author. MY, LZ; extracted 
the data and wrote the manuscript together: $\mathrm{BX}$; made the figures: $\mathrm{YJi}$; made the references review: $\mathrm{BX}, \mathrm{ZCXu}$; had important intelligent contributions and critically revised the manuscript. All authors in read and approved the final manuscript.

\section{Conflicts of interest}

The authors declared no conflict of interest.

\section{REFERENCES}

1. Riazmontazer N, Bedayat G. Aspiration cytology of an enlarged thymus presenting as a mediastinal mass. A case report. Acta Cytol 1993; 37: 427-430.

2. Regal MA. Gigantic enlargement of the thymus gland. Saudi Med J 2007; 28: 1587-1589.

3. Judd RL. Massive thymic hyperplasia with myoid cell differentiation. Human Pathol 1987; 18: 11801183.

4. Pedroza Meléndez A, Larenas-Linnemann D. Thymus hyperplasia, differential diagnosis in the wheezing infant. Allergol Immunopathol (Madr) 1997; 25: 59-62.

5. Tan Z, Ying LY, Zhang ZW, Li JH, Gao Z, Qi JC. True thymic hyperplasia in an infant. J Pediatr Surg 2010; 45: 17111713.

6. Linegar AG, Odell JA, Fennell WM, et al. Massive thymic hyperplasia. Ann Thorac Surg 1993; 55: 11971201.
7. Weissferdt A, Moran CA. Thymic hyperplasia with lymphoepithelial sialadenitis (LESA)-like features: a clinicopathologic and immunohistochemical study of 4 cases. Am J Clin Pathol 2012; 138: 816-822.

8. Tadiotto E, Clemente M, Pecoraro L, Piacentini G, Degani D, Pietrobelli A.Massive thymic hyperplasia in a 15monthold boy: case report and literature review. Clin Case Rep 2019; 7: 27-31.

9. Lee $Y$, Moallem S, Clauss RH. Massive hyperplastic thymus in a 22-month-old infant. Ann Thorac Surg 1979; 27: 356-358.

10. Szarf G, Mussi de Andrade TC, De Oliveira R, Ota LH, Lederman HM. Massive thymic hyperplasia presenting with respiratory insufficiency in a 2yearold child. Thorax 2010; 65: 555-556.

11. Katz SM, Chatten J, Bishop HC, Rosenblum H. Report of a case of gross thymic hyperplasia in a child. Am J Clin Pathol 1977; 68: 786790.

12. Lamesch AJ. Massive thymic hyperplasia in infants. Z Kinderchir 1983; 38: 16-18.

13. Lee YM, Koh MT, Omar A, Majid A. Hyperplasia of thymic gland. Singapore Med J 1996; 37: 288290.

14. Woywodt A, Verhaart S, Kiss A. Massive true thymic hyperplasia. Eur J Pediatr Surg 1999; 9: 331-333.

15. Sayed S, Sharma V, McBride CA, Levitt D, Alphonso $\mathrm{N}$. Massive thymic hyperplasia in a neonate with BeckwithWiedemann syndrome. J Paediatr Child Health 2016; 52: 90-92.

16. Weis CA, Märkl B, Schuster T, Vollert K, Ströbel P, Marx A. "Echte Thymushyperplasie" Differenzialdiagnose der thymusvergrößerung bei säuglingen und Kindern. Pathologe 2017; 38: 286293. 